\title{
Editorial: The Future of PAGES - Setting New Directions
}

PAGES is a service-oriented program that facilitates interdisciplinary science across international boundaries. Its goal is to support research aimed at understanding the Earth's past environments in order to make predictions for the future. This research support is not the traditional kind i.e., in the way of research funds; rather, we support the paleoscience community by developing the ways and means for collaboration and communication. PAGES supports scientists via sponsorship of workshops, symposia, and conferences that bring scientists from different countries together to share, compare and synthesize data from different high resolution archives recording climate change; it is especially about building up a science community that interacts on an international level. Many scientists already collaborate internationally without PAGES as a venue and this we recognize and applaud. However, the larger role for PAGES is in facilitating dialog among all scientists, including those who might not otherwise focus on common interdisciplinary themes and initiatives between countries.

PAGES, founded in 1991, has had a successful history due to the scientific vision of earlier members of the SSC and the IPO. But what will happen in the future? How can we improve on our success? How can PAGES best serve the needs of the widest possible international and interdisciplinary paleoscience community? What doYOU think about PAGES? What doYOU expect from PAGES in the future? Perhaps you have thought about a new crosscutting theme that could be developed into a new initiative within PAGES.

You may have received our E-news request for feedback (vol. 2004, No.1), or seen the EOS article (March 16, page 107), but to date, we have had only 40 responses from over 3500 subscribers. Your input is needed and essential to crafting the future of PAGES and would be greatly appreciated before 1 MAY 2004! Please go to our feedback site on the web: http://www.pages.unibe.ch/about/feedback.html or email your comments to Leah Christen (christen@pages.unibe.ch). Feedback can also be sent by fax (+4131312 31 68), or regular mail (Sulgeneckstrasse 38, 3007 Bern, Switzerland). Please take the time to send us your comments (good and bad) so that we can help shape PAGES' future together.

Julie Brigham-Grette (New PAGeS Chair) University of Massachusetts, USA; juliebg@geo.umass.edu

\section{THE CLIMATE OF THE NEXT MILLENNIA IN THE PERSPECTIVE OF ABRUPT CLIMATE CHANGE DURING THE LATE PLEISTOCENE}

\author{
PAGES/DEKLIM Conference: 7-10 March 2005, Mainz, Germany \\ Convenors: Frank Sirocko, Jerry McManus, Martin Claussen, Keith Alverson
}

\section{Call for Papers}

"The climate of the past is the key to understanding the climate of the future". Is this often used statement truly correct for the next two millennia? The conference will examine past records of abrupt climate change and discuss if the processes that caused past abrupt change are indeed relevant for the Holocene and predicted climate evolution. Keynote lectures on the mechanisms that dominated past climate evolution will be followed by sessions (talks and posters) on long (0-3 ma), medium (0-150 ka) and very short (Holocene and last millennium) time scales. Discussions are intended to separate processes unique to the past from those that indeed have the potential to effect global climate during the next millennia. The conference is sponsored by the German DEKLIM program (www.deklim.de) and represents a German contribution to PAGES. We hope to welcome you in Mainz (50 minutes from Frankfurt International Airport) and would appreciate your early registration.

\section{Registration}

To receive a registration form for the conference, please send an email with your full address to the DEKLIM-EEM secretary, Saskia Rudert (email: rudert @ uni-mainz.de). The registration form can also be downloaded at http: //www.uni-mainz.de/FB/Geo/Geologie/sedi/en/index.html.

Conference fees are 75 Euro. The excursion costs 30 Euro, plus accommodation. There is a limited amount of support available to finance the participation of students. If you would like to apply for support, please put in a formal request. Abstracts should be no more than 1 page of text and 1 page of figures.

\section{Deadlines: for registration - 31 0ctober 2004; for abstract submission - 30 November 2004 \\ Further Information: http://www.pages.unibe.ch/calendar/2005/deklim.html}

